\title{
The effects of perceptual set on the shape and apparent depth of subjective contours
}

\author{
STANLEY COREN \\ University of British Columbia, Vancouver, British Columbia, Canada \\ CLARE PORAC \\ University of Victoria, Victoria, British Columbia, Canada \\ and \\ LEONARD H. THEODOR \\ York University, Downsview, Ontario, Canada
}

\begin{abstract}
Two experiments showed the influence of perceptual set on the perception of subjective contours. In the first, the perceived shape of a subjective-contour figure (a minimal version of the Ehrenstein configuration) was varied by altering the observer's viewing set. The second experiment showed that apparent depth emerged in subjective-contour figures when observers were set to perceive the illusory contours.
\end{abstract}

The past decade has seen an increased interest in stimulus configurations that produce subjective or illusory contours. Subjective contours are lines or edges perceived in regions of an array where there is no physical luminance or color gradient. Figure 1 shows examples of subjective contours. Figure $1 \mathrm{~A}$ is a subjective-contour square, Figure 1B spells the word FEET in subjective-contour letters, and the apparent cliff edge in Figure $1 \mathrm{C}$ is also one of these illusory contours.

Two groups of hypotheses attempt to explain subjective contours. The first attributes their existence to physiological mechanisms. Most subjective-contour figures show systematic brightness effects; therefore, the same mechanisms that account for brightness contrast have been used to explain the emergence of these figures (Brigner \& Gallagher, 1974; Coren \& Theodor, 1977; Day \& Jory, 1978, 1980; Frisby \& Clatsworthy, 1975; Jory \& Day, 1979). Other investigators have suggested that subjective contours arise from the interactions among the receptive fields of orientation-specific cortical cells (Jung; 1973; Jung \& Spillman, 1970; Kennedy, 1979; Smith \& Over, $1975,1979)$ or that they are due to Fourier analysis processes in the visual system (Becker \& Knopp, 1978; Ginsburg, 1975). In general, these structural theories have not fared well against recent findings. Brightness-contrast

\footnotetext{
The authors are listed in alphabetical order. This research was supported, in part, by grants from the Natural Sciences and Engineering Research Council of Canada. The authors thank Miriam Blum-Steele and Susan Dixon for their assistance in data collection and manuscript preparation. We would also like to thank one of our anonymous reviewers, who detected a major statistical error in the first version of this manuscript, thus providing us with the opportunity to correct it. Requests for reprints should be sent to Stanley Coren, Psychology Department, University of British Columbia, Vancouver, B.C., Canada V6T 1W5.
}

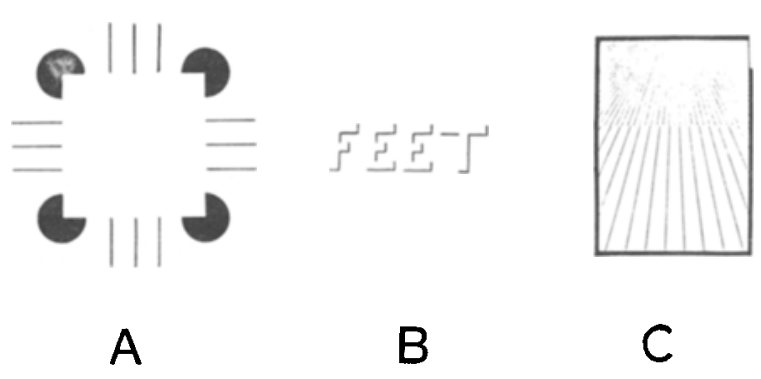

Figure 1. (A) A subjective-contour square, (B) the word FEET in subjective contour letters (adapted from Coren, 1972), (C) this apparent cliff is a subjective contour (adapted from Coren, 1972).

explanations do not explain why objective-contour figures, which should maximize brightness contrast, do not produce brightness effects analogous to those observed in subjective-contour patterns (Coren \& Theodor, 1975). Several investigators have presented subjective figures in the absence of the requisite brightness differences called for by such theories (Parks, 1980; Spillman \& Redies, 1981; Ware, 1980). Edge-detector interactions are unlikely explanations for these illusory effects, since blurring often improves the contour strength (Spillman, 1975). Also, the Fourier analysis argument has been weakened by the appearance of subjective contours without the relevant low-spatial-frequency component (Parks $\&$ Pendergrass, 1982). Finally, there are a variety of subjectivecontour-inducing patterns that produce two or more possible sets of subjective contours, often alternating or fluctuating in consciousness (e.g., Bradley \& Dumais, 1975; Bradley \& Petry, 1977; Meyer \& Phillips, 1980; Sambin, 1974), which provide explanatory difficulties for any 
simple physiological feature processing theory (see also Bradley, Dumais, \& Petry, 1976; Cavonius, 1976).

A counterposition to these physiological mechanisms is the second group of hypotheses based on cognitive processes. Kanizsa $(1974,1976)$ suggests that illusory contours arise because of the operation of amodal perception, a principle analogous to the Gestalt law of closure. Other theorists view the perception of the subjective-contour figure as some form of problem solving or unconscious inference. Accordingly, the figure is abstracted from inferences provided by the partial figural cues present in the stimulus arrays, in much the same manner as meaningful configurations are extracted from incomplete outline drawings of cartoons (Bradley \& Dumais, 1975; Gregory, 1972; Kennedy, 1976; Piggins, 1975; Rock \& Anson, 1979).

Coren (1972) suggested another cognitive theory. He noted that most subjective-contour figures contain implicit depth cues. Thus, Figure 1A contains implicit interposition cues, Figure 1B, shadowing cues, and Figure 1C, texture gradient cues. According to this line of reasoning, the subjective contours emerge when the observer perceptually reorganizes the configuration according to these implied cues. The resulting three-dimensional percept is simpler, in informational terms, than the actual two-dimensional array (cf. Hochberg \& Brooks, 1960).

Coren's theoretical position is supported by several lines of data. Indirect measures, involving stimuli placed on or beside illusory figures, have shown that size constancy mechanisms are activated by the apparent depth in subjective-contour arrays (Coren, 1972; Parks, 1985; Porac, 1978). Other investigators have directly manipulated the depth cues in a stereoscopic paradigm. When subjective contours were viewed in a stereoscope, where binocular disparity cues were in directional conflict with the implicit depth in the pattern, the subjective contours tended to disappear; increasing the disparity tends to increase the strength of the apparent contour. These are the expected results if the depth organization of the array is vital to the etiology of the illusory figure (Gregory \& Harris, 1974; Lawson, Cowan, Gibbs, \& Whitmore, 1974; Whitmore, Lawson, \& Kozora (1976). Although there are occasional exceptions for certain unique stimulus configurations (e.g., Ware \& Kennedy, 1977), direct experimental measures seem to confirm the presence of apparent depth in the vast majority of subjective-contour configurations. For example, Halpern (1981) asked subjects to reproduce the apparent depth between the illusory figure and its background by marking off a length on a ruled horizontal line. Coren and Porac (1983) used a binocular point of light that was adjustable in depth by the observer. This point of light was superimposed on the subjectivecontour figure or on the background. The results of these studies indicated that when a subjective contour was present, there was a difference in apparent depth.

Another informal line of evidence supports cognitive explanations of subjective contours. Coren (1974) noted the possible operation of perceptual set in some subjective- contour figures. Consider Figure 1B, which spells the subjective-contour word, FEET. An individual who is unfamiliar with the English alphabet would probably see this configuration as a collection of black lines. A similar effect can be shown with Figure $2 \mathrm{~A}$. If individuals have been set by prior instructions to count the number of black figures in a series of arrays, they see $2 \mathrm{~A}$ as a collection of five black figures rather than the subjective-contour word, FLY, seen by most English speakers. The reverse of this effect can be demonstrated using $2 B$. There, as noted by Coren (1972), most individuals do not see a subjective-contour triangle when shown this figure in iso-
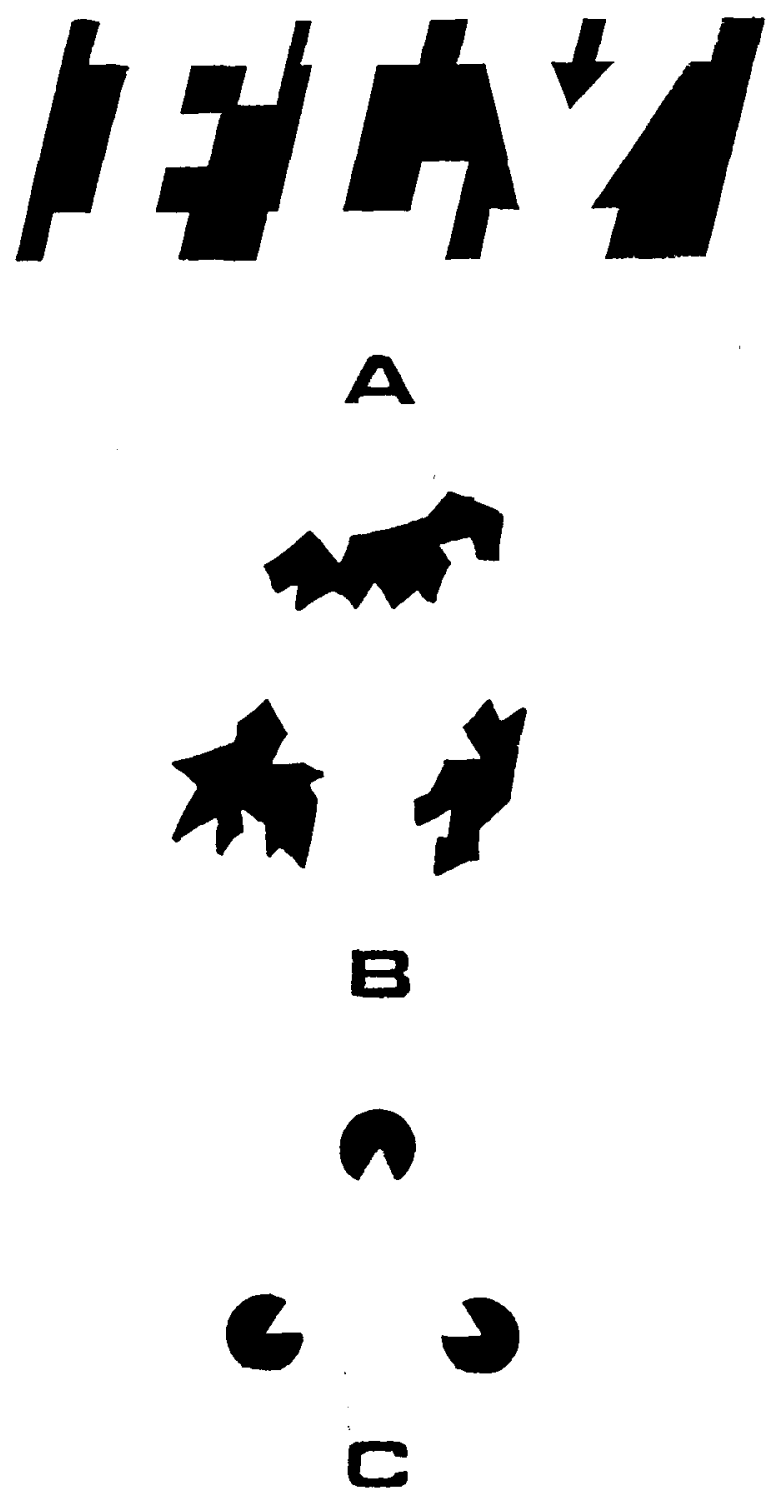

Figure 2. (A) The word FLY appears in subjective contours unless observers are set to see black figures; (B) a figure in which observers seldom see a subjective contour triangle spontaneously unless set by the prior presentation of subjective-contour figures such as (C). 
lation. However, when shown a series of other subjective contour configurations (such as $2 \mathrm{C}$ ) beforehand, a percentage of individuals report seeing a subjective triangle of low salience in 2B. Unfortunately, most of the demonstrations of the effect of perceptual set on the appearance of subjective contours are as informal and anecdotal as those presented above (Landauer, 1978; Parks, 1984). The following experiments were conducted to provide formal experimental measures of the operation of perceptual set on the appearance of subjective contours.

\section{EXPERIMENT 1}

As we noted above, subjective-contour-inducing arrays induce the perception of forms, lines, or figures in the absence of physical variations in stimulus intensity. This first experiment tested the lability of the actual shape of the perceived subjective figures. We began with a configuration in which the perceived illusory figures are not well defined; this figure is a variant of a pattern offered by Ehrenstein (1941) and is shown in Figure 3A. Observers frequently report the appearance of white circles at the point where the lines should intersect; however, this percept is not universal. Occasionally, observers report only a set of broken dashed lines or amorphous brightenings at the intersections. When the existence of figures at these intersections is suggested, most observers readily reorganize the percept and report the existence of white, subjective circles overlapping the intersections of the lines. The fact that many observers require prompting before they report a subjective contour in this configuration is itself interesting, and tends to support the operation of perceptual set in this context. The simplest inducing configuration for the appearance of a subjective contour that can be extracted from this array is similar
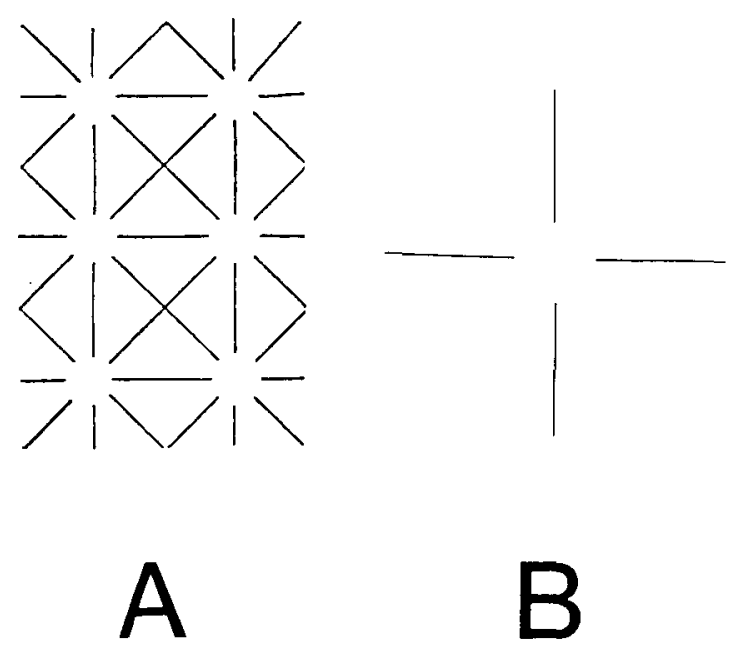

Figure 3. (A) A series of white subjective circles is usually reported in this figure (adapted from Ehrenstein, 1941). (B) A minimal configuration for the perception of a subjective contour where the perceived shape is a circle, square, or amorphous blob; this figure was used as the stimulus in Experiment 1. to Figure 3B. In 3B, there are two alternative perceptual organizations. Either one sees four short unitary line elements arranged along the horizontal and vertical axes or one can see two continuous line segments that orthogonally intersect with a white subjective contour figure interposed in front of the intersection. If the latter perceptual organization is adopted, there is insufficient information in the array to specify the shape of the occluding figure. It could be a circle, square, diamond, or an amorphous "blob." Cognitive processing theories of subjective contours predict that the specific form of the figure perceived by the observer depends on assumptions made while viewing the configuration. Neural interactive theories, on the other hand, assert that the shape and phenomenal appearance of the subjective figure is determined by the underlying neural processes and hence should be independent of the viewing set of the observer.

\section{Method}

Figure 3B shows the stimulus configuration used in this experiment. The stimulus lines were $0.5 \mathrm{~mm}$ thick and $1 \mathrm{~cm}$ long. The central gap was $6 \mathrm{~mm}$ wide. The configuration was centered on a page of white paper $21.5 \times 28 \mathrm{~cm}$ and printed in black ink $(7.2 \%$ reflectance). Each stimulus was presented in a booklet and preceded by one of three versions of the following set-inducing instruction:

\footnotetext{
On the following page you will see a pattern composed of four black lines and a central area. Look at the central area carefully. Many people report seeing a white figure in that region. If you see any white figure after studying the figure for a few moments, outline the figure with your pen or pencil. If you can't see the white figure after looking at the pattern for a few moments, check the space provided in the lower right hand corner of the next page.
}

The above instruction was designed for the group without a specific figural set induction. The other two versions of the instruction sheet differed in the substitution of one word. The one occurrence of the word "figure" (italicized in the above instruction but not in the actual test booklet) was replaced with either the word " "square" or with the word "circle." Thus, the observer received a neutral perceptual set for a subjective figure at the locus of the intersection of the lines or a specific set for a square or a circle. In addition, a space was provided in the lower right-hand corner of the page reading "Check here if you see nothing."

One hundred sixty-two undergraduate volunteers participated in this experiment. Each received only one form of the set instruction and each produced only a single response.

\section{Results and Discussion}

Each response was classified as a circle, a square, amorphous (including general "blob" types of figures), or no figure. The square category included both outline squares drawn with the bottom line parallel to the edge of the page or squares rotated $45^{\circ}$ to form a diamond configuration, since no particular orientation of the square had been set in the instructions. All responses were classifiable, and only 1 observer had to be discarded because of a multiple response. This latter observer was not included in subsequent analyses. The data from the remaining $161 \mathrm{ob}-$ servers are presented in Table 1.

The data in Table 1 indicate that instructional set interacted with the shape of the perceived subjective-contour figure. These differences were statistically reliable $\left[\chi^{2}(4)\right.$ 
Table 1

Figural Responses as a Function of Set

\begin{tabular}{lllllllll}
\hline & \multicolumn{6}{c}{ Figure Reported } \\
\cline { 2 - 7 } \multicolumn{1}{c}{ Set } & Circle & \multicolumn{2}{c}{ Square } & Amorphous & No Figure & Total N \\
\hline Neutral & $39 \%$ & $(20)$ & $4 \%$ & $(2)$ & $8 \%(4)$ & $49 \%(25)$ & 51 \\
Circle & 67 & $(39)$ & 0 & & 0 & 33 & $(19)$ & 58 \\
Square & 10 & $(5)$ & 38 & $(20)$ & 0 & 52 & $(27)$ & 52 \\
\hline
\end{tabular}

Note-Table entries are the percentage of each set group giving each of the possible responses. Numbers in parentheses indicate the raw number of responses in each category.

$=59.1, p<.005]$, excluding the amorphous category for which response rates produced expected frequencies that were too low for reliable analysis [including the amorphous responses with the "no-figure"' responses produces a virtually identical level of significance, with $\chi^{2}(4)=$ $61.6, p<.005$ ]. When observers were given neutral instruction, approximately half ( $49 \%)$ did not report seeing a figure in this minimal array. Thirty-nine percent (or $76 \%$ of those who saw any subjective-contour figure in this group) reported the perception of a circle under neutral set conditions. When set specifically for a circle, the reports of a circular subjective contour significantly increased to $67 \%$; this percentage comprised $100 \%$ of those who saw an illusory figure under circle set instructions $(z=2.93, p<.01)$. The proportion of observers who failed to perceive a figure was reduced from $49 \%$ in the neutral-set group to $33 \%$ in the circle-set group. This effect is somewhat weaker, and is significant in a one-tailed test $(z=1.73, p<.05)$. On the other hand, when observers were set to see a square, the number of circle responses dropped, relative to the neutral set, to $10 \%$ $(z=3.50, p<.001)$. The response "square" increased to $38 \%$ (80\% of observers reporting an illusory figure in this group). This increase in the "square" response was more dramatic when compared with its minimal presence under the neutral-set instructions, and this difference is significant $(z=4.28, p<.001)$. In the circle set, you will notice, the square response is totally absent. Thus, if an observer saw a subjective contour in the test stimulus, he or she was biased toward seeing the one predicted from the set instructions.

\section{EXPERIMENT 2}

The results of Experiment 1 show a reasonably convincing association between the apparent shape of an ambiguous subjective-contour figure and the induction of a specific perceptual set. However, one might argue that the induction, "Many people see a white (figure)," could influence some individuals to respond that they see the particular figure on the basis of social conformity rather than as an actual perceptual response. Although informal interviews with a subsample of observers suggested that they "saw" the figure coincident with the appropriate perceptual set, an additional experiment with an indirect set induction and dependent measure seemed necessary to cross-validate the results of Experiment 1.

Since there is both direct and indirect evidence that the appearance of subjective contours is accompanied by a segregation of the array into depth (Coren, 1972; Coren \& Porac, 1983; Halpern, 1981; Parks, 1985; Parks \& Marks, 1985; Porac, 1978), this phenomenal depth segregation became the dependent measure for the appearance of the subjective contours in Experiment 2.

\section{Method}

Apparatus. The test stimulus was a varient of Figure 3B used by Kennedy (1978). This configuration has 8 lines instead of 4 and is shown in Figure 4D. Figure 4D produces the perception of a white circle interposed in front of a starburst of lines; however, a number of observers require prompting to see this organization.

We used an apparatus similar to that used by other investigators in attempting to assess apparent depth in parts of configurations (Coren \& Festinger, 1967; Gregory, 1966; Kilbride \& Leibowitz, 1975). We had used it to directly assess apparent depth in subjectivecontour arrays in previous research (Coren \& Porac, 1983). The procedure involved the superimposition of a binocular target on a monocular stimulus pattern and the assessment of the depth characteristics. The binocular target, which was adjusted in apparent depth, was imaged over components of the stimulus figure. Observers set the adjustable binocular target until it was at the same phenomenal depth as the portion of the stimulus array where it was positioned. The apparatus used to make these depth adjustments is shown in Figure 5A.

Stimuli were prepared as slides and projected on a rear-projection screen with polarizing material mounted in front of it. The image of the adjustable depth stimulus spot was reflected to observers' eyes with a half-silvered mirror, through which the polarized monocular stimulus pattern was also visible. A pair of orthogonally oriented Polaroid filters were placed in a viewing port. This allowed the experimental stimuli to be seen by one eye while the depth spot was seen by both eyes. This target appeared as a virtual point source (provided by a red filtered, extremely small tungsten lamp, often referred to as a grain-of-wheat bulb). The observer varied the apparent distance of the binocular spot by adjusting its position laterally along an optical bench rail. The position of the spot provided
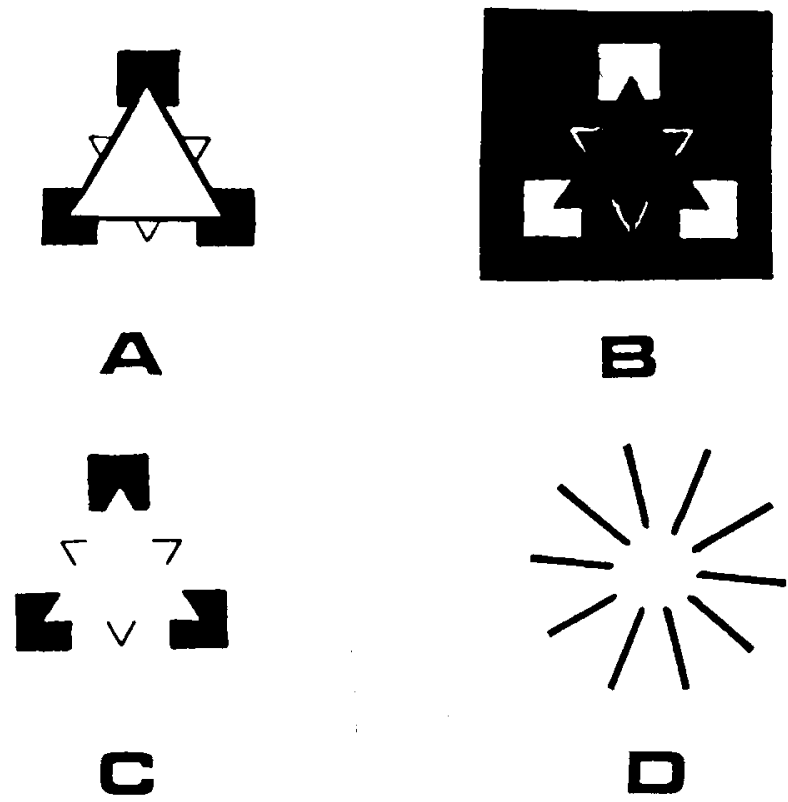

Figure 4. (A) Objective triangle pattern (after Porac, 1978); (B and C) subjective contour triangles (after Coren, 1972); (D) a subjective-contour pattern that can be seen as a circle (after Kennedy, 1978). All figures served as stimuli in Experiment 2 and were presented in the order given here. 

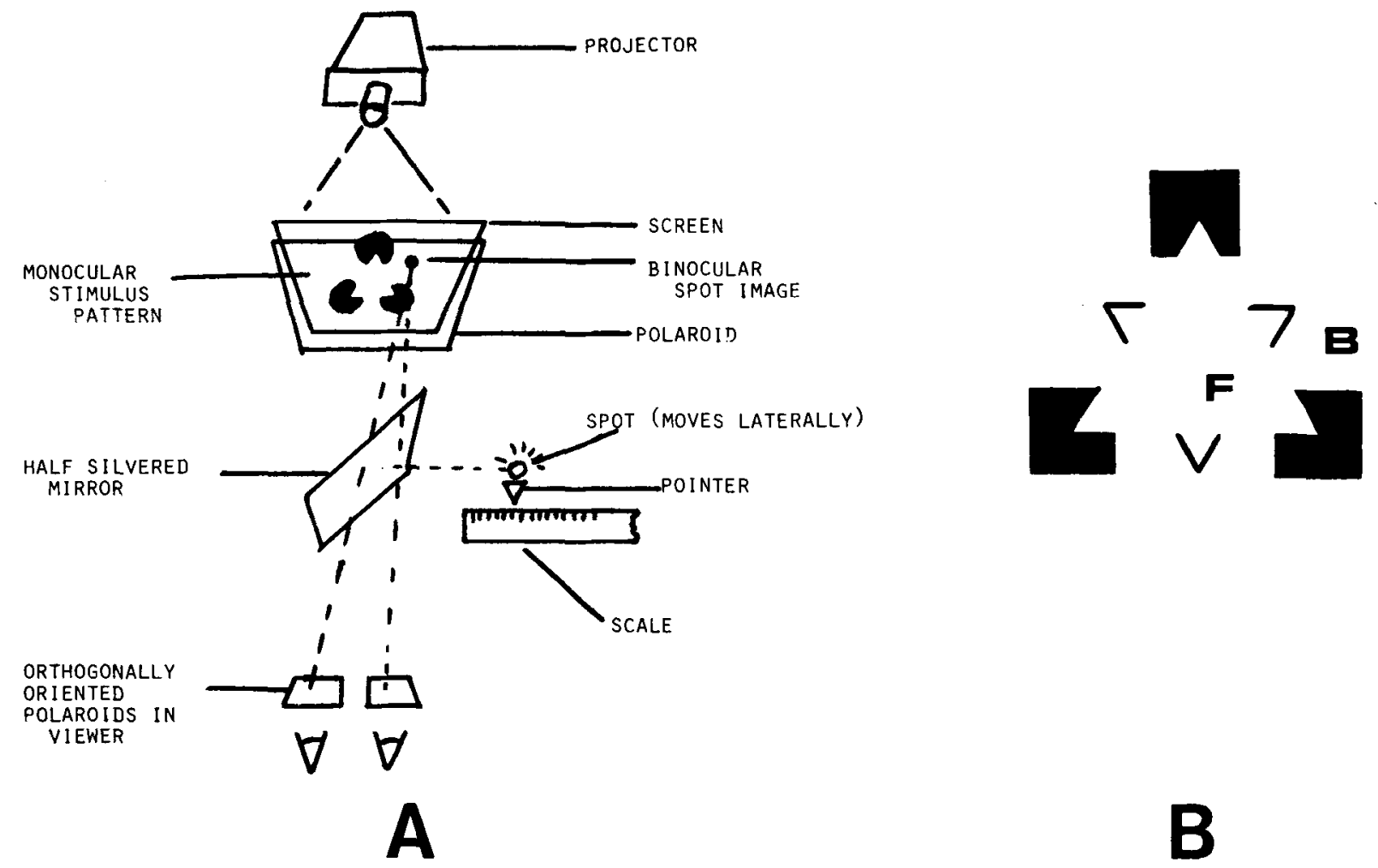

Figure 5. (A) The apparatus used to measure the apparent depth of parts of the subjective-contour figure; a binocular marker was superimposed on a monocular stimulus. (B) The placement of the test spot was either on the figure in the pasition marked $F$ or on the background in the position marked $B$.

the measurement of apparent depth in millimeters. To determine the apparent difference in depth between the figure and the background, the spot was imaged on the figure $1^{\circ}$ to the inside of the subjective contour (a location marked $\mathrm{F}$ in Figure $5 \mathrm{~B}$ ) or $1^{\circ}$ to the outside of the subjective contour (a location marked $B$ in 5B).

Procedure and Subjects. In neither group was any explicit set given, either as to the figures to be seen or as to any expected depth differences among parts of the configuration. Rather, this study used an indirect set induction. The session began with a series of practice trials in which observers made settings on the apparent distance of an outline square and a black line. When set was not induced, the test figure (4D) was presented and four measurements of the relative apparent depth of the figure and the background were taken. The set-induction group first saw a real-contour figure (4A) followed by two subjective-contour figures (4B and 4C). The observers made the same depth judgments on each of these arrays as they made on the test figure (4D). It was assumed that the prior presentation of subjective-contour figures would "set" observers to perceive subjective contours. This would then manifest itself in the appearance of a depth segregation between illusory figure and background for the test figure as well.

Forty paid observers participated in this study. Each had acuity of at least 20/25 and normal stereopsis, as measured with a Keystone Telebinocular. Twenty of them served in the no-set condition, and 20 served in the set-induction sequence.

\section{Results and Discussion}

First, we confirmed the fact that the experimental technique was sensitive to apparent depth differences by replicating the findings of Coren and Porac (1983) for both of the nonambiguous subjective-contour figures (4B and
4C). The illusory contour was seen as closer than the background for both of these figures (31.2 vs. $41.8 \mathrm{~mm}$ for figure and background, respectively, for $4 \mathrm{~B}$, and $31.6 \mathrm{vs.}$ 41.9 for $4 C$ ). These results were statistically significant [ts $(19)=4.39$ and 4.46 for $4 B$ and $4 C$, respectively, with $p<.01$ for both].

The set-induction results with Figure 4D were unambiguous. The no-set group did not display a significant apparent depth segregation [31.5 vs. $32.2 \mathrm{~mm}$ for figure and background respectively, $t(19)=0.42]$. Informal interviews with observers supported the absence of an illusory figure for approximately $50 \%$ of the observers. The set-induction group, which had the test figure presented in the context of other subjective-contour figures, showed a significant difference between the apparent depth of the subjective-contour figure and the background [31.7 vs. $37.4 \mathrm{~mm}$ for figure and background respectively, $t(19)$ $=3.10, p<.01$ ). Furthermore, observers' reports confirmed that most of this group perceived an illusory figure. When we directly compare the two groups, the overall amount of depth seen by the implicit-set group is significantly greater than that seen by the no-set group [t(38) $=2.03, p<.05$ ].

\section{GENERAL DISCUSSION}

The two experimental results are consistent. Perceptual set influences the appearance of subjective-contour 
figures. The first experiment used an explicit set induction and found that the apparent shape of the illusory figure was influenced by set when the subjective-contour array was ambiguous. The second experiment used an indirect set induction and dependent variable. Here, perceptual set was manipulated by showing an ambiguous array in the context of unambiguous subjective-contour configurations versus presentation without this context. The dependent measure was the appearance of depth segregation in the array. Once again, set induction resulted in the perception of a subjective figure and its secondary apparent depth effects.

These results have theoretical implications beyond the issue of perceptual set itself. A structural or physiological interpretation of subjective contours is not flexible enough to explain these results. One cannot predict that interactions between orientation-specific receptors, lateral inhibitory effects, or the low-frequency components of a Fourier analysis of the patterns should change as a function of observer set or expectations. Thus, structural explanations, as the complete cause of subjective contour formation, are made less plausible by the present data.

These results are consistent with cognitive explanations of subjective-contour formation; however, they do not permit a clear differentiation among the various theoretical positions. Investigators who maintain that subjective contours are a form of problem solving or unconscious inference, those who view them as a form of Gestalt closure, and those who feel that subjective contours arise from the reorganization of the configuration on the basis of implicit depth cues can accommodate the operation of perceptual set. The fact that a cognitive experiential variable influences the appearance of subjective contours strengthens the position of those theorists who ascribe these illusory figures to conceptually driven processing. One of the interesting ancillary findings of Experiment 2 concerned the emergence of apparent depth relationships only when observers were set to perceive a subjective-contour figure. This result supports the notion that depth segregation is intricately bound to the cognitive process that produces subjective contours. It may be a primary factor, which actually induces the perception of the contour, or it may work in cooperation with figural closure or hypothesis testing to provide meaning to an otherwise ambiguous array. In any event, the fact that perceptual set can modify the perception of subjective contours should be taken as an indication that higher level cognitive processing, rather than simple structural interactions, is responsible for the appearance of these illusory forms and figures.

\section{REFERENCES}

BeCKer, M. F., \& KNOPP, J. (1978). Processing of visual illusions in the frequency and spatial domains. Perception \& Psychophysics, 23, 521-526.

Bradley, D. R., \& Dumais, S. F. (1975). Ambiguous cognitive contours. Nature, 257, 582-584.

Bradley, D. R., Dumais, S. T., \& Petry, H. M. (1976). Response to Cavonius. Nature, 261, 78.
Bradley, D. R., \& Petry, H. M. (1977). Organizational determinants of subjective contour: The subjective Necker cube. American Journal of Psychology, 90, 254-262.

Brigner, W. L., \& Gallagher, M. B. (1974). Subjective contour: Apparent depth or simultaneous contrast? Perceptual \& Motor Skills, 38, 1047-1053.

Cavonius, C. R. (1976). Ambiguous cognitive contours. Nature, 261, 77-78.

CoRen, S. (1972). Subjective contour and apparent depth. Psychological Review, 79, 359-367.

Coren, S. (1974). Reply to Banks and Coffin. Psychological Review, 81, 266.

Coren, S., \& Festinger, L. (1967). An alternate view of the "Gibson normalization effect." Perception \& Psychophysics, 2, 621-626.

Coren, S., \& Porac, C. (1983). Subjective contours and apparent depth: A direct test. Perception \& Psychophysics, 33, 197-200.

COREN, S., \& TheODor, L. (1975). Subjective contour: The inadequacy of brightness contrast as an explanation. Bulletin of the Psychonomic Society, 6, 87-89.

Coren, S., \& Theodor, L. H. (1977). Neural interactions and subjective contours. Perception, 6, 107-111.

DAY, R. H., \& JoRY, M. K. (1978). Subjective contours, visual acuity, and line contrast. In J. C. Armington, J. E. Krauskopf, \& B. Wooten (Eds.), Visual psychophysics and physiology (pp. 331-340). New York: Academic Press.

DAY, R. H., \& JORY, M. K. (1980). A note on a second stage in the formation of illusory contours. Perception \& Psychophysics, 27, 89-91.

EhrensteIN, W. (1941). Über Abwandlungen der L. Hermannschen Helligkeitersheinung. Zeitschrift für Psychologie, 150, 83-91.

Frusby, J. P., \& Clatsworthy, J. L. (1975). Illusory contours: Curious cases of simultaneous brightness contrast? Perception, 4, 349-357.

GinsBURG, A. P. (1975). Is the illusory triangle physical or imaginary? Nature, 257, 219-220.

Gregory, R. L. (1966). Visual illusions. In B. Foss (Ed.), New horizons in psychology. Baltimore: Penguin.

Gregory, R. L. (1972). Cognitive contours. Nature, 238, 51-52.

GrEGory, R. L., \& HARRIS, J. B. (1974). Illusory contours and stereo depth. Perception \& Psychophysics, 15, 411-416.

HALPERN, D. F. (1981). The determinants of illusory-contour perception. Perception, 10, 199-213.

HochberG, J., \& Brooks, V. (1960). The psychophysics of form: Reversible-perspective drawings of spatial objects. American Journal of Psychology, 73, 337-354.

JoRY, M. K., \& DAY, R. H. (1979). The relationship between brightness contrast and illusory contours. Perception, 8, 3-9.

JuNG, R. (1973). Neurophysiology and perception. In R. Jung (Ed.), Handbook of sensory physiology (Vol. 3, Part A, pp. 1-169). New York and Berlin: Springer.

Jung, R., \& Sillman, L. (1970). Receptive-field estimation and perceptual integration in human vision. In F. A. Young \& D. B. Lindsley (Eds.), Early experience and visual information processing in perceptual and reading disorders (pp. 181-197). Washington, DC: National Academy of Science.

Kanizsa, G. (1974). Contours with gradients or cognitive contours? Italian Journal of Psychology, 1, 93-112.

KANIZsA, G. (1976). Subjective contours. Scientific American, 235(4), 48-52.

KENNEDY, J. M. (1976). Attention, brightness and the constructive eye. In M. Henle (Ed.), Vision and artifact (pp. 33-48). New York: Springer.

Kennedy, J. M. (1978). Illusory contours and the ends of lines. Perception, 7, 605-607.

KENNEDY, J. M. (1979). Subjective contours, contrast and assimilation. In C. F. Nodine \& D. F. Fisher (Eds.), Perception and pictorial representation (pp. 167-195). New York: Praeger.

KILBRIDE, P. L., \& Leibowitz, H. W. (1975). Factors affecting the magnitude of the Ponzo illusion among the Baganda. Perception \& Psychophysics, 17, 543-548.

LANDAUER, A. A. (1978). Subjective states and the perception of subjective contours. In J. P. Sutcliffe (Ed.), Conceptual analysis and 
method in psychology: Essays in honor of W. M. ONeil (pp. 142-146). Sydney: Sydney University Press.

Lawson, R. B., Cowan, E., GibBs, T. D., \& Whitmore, C. G. (1974). Stereoscopic enhancement and erasure of subjective contours. Journal of Experimental Psychology, 103, 1142-1146.

Meyer, G. E., \& Philuips, D. (1980). Faces, vases, subjective contours and the McColl righ effect. Perception, 9, 603-606.

PARKs, T. E. (1980). Subjective figures: Some unusual concomitant brightness effects. Perception, 9, 239-241.

PARKS, T. E. (1984). Illusory figures: A (mostly) atheoretical review. Psychological Bulletin, 95, 282-300.

PARKS, T. E. (1985). Apparent depth and texture differences in illusory figure patterns: A paradox resolved. Perception \& Psychophysics, 37, 568-570.

PARKs, T. E., \& Marks, W. (1985). Illusory figures: Individual differences in apparent depth and lightness. Perception \& Psychophysics, 37, 529-532.

Parks, T. E., \& Pendergrass, L. (1982). On the filtered components approach to illusory visual contours. Perception \& Psychophysics, 32, 491-493.

Piggins, D. J. (1975). Cognitive space. Perception, 4, 337-340.

PORAC, C. (1978). Depth in objective and subjective contour patterns. Bulletin of the Psychonomic Society, 11, 103-105.
Rock, I., \& ANSON, R. (1979). Illusory contours as the solution to a problem. Perception, 8, 665-681.

SAMBIN, M. (1974). Angular margins without gradient. Italian Jour-. nal of Psychology, 1, 355-361.

SMITH, A. T., \& OVER, R. (1975). Tilt aftereffects with subjective contours. Nature, 257, 581-582.

SMith, A. T., \& OVER, R. (1979). Motion aftereffect with subjective contours. Perception \& Psychophysics, 25, 95-98.

Spillman, L. (1975). Perceptual modification of the Ehrenstein illusion. In S. Ertel, L. Kemmler, \& M. Stadler (Eds.), Gestalttheorie in der modernen Psychologie (pp. 210-218). Darmstadt: Steinkopff.

SpIllman, L., \& Redies, C. (1981). Random-dot motion displaces Ehrenstein illusion. Perception, 10, 411-415.

WARE, C. (1980). Coloured illusory triangles due to assimilation. Perception, 9, 103-107.

WARE, C., \& KENNEDY, J. M. (1977). Illusory line linking solid rods. Perception, 6, 601-602.

Whitmore, J. M., Lawson, R. B., \& Kozora, C. E. (1976). Subjective contours in stereoscopic space. Perception \& Psychophysics, 19 , 211-213.

(Manuscript received January 16, 1986; revision accepted for publication April 17, 1986.) 